\title{
CUIDANDO COM ARTE: a promoção da saúde por meio da música
}

\author{
Amanda Vieira Macedo CARDOSO ${ }^{1}$
}

Ana Augusta Maciel de SOUZA ${ }^{2}$

Patrick Leonardo Nogueira da SILVA ${ }^{3}$

Helder Leone Alves de CARVALHO

Elioenai Dornelles ALVES ${ }^{5}$

Wilson AGUIAR FILHO ${ }^{6}$

\begin{abstract}
${ }^{1}$ Enfermeira. Universidade Estadual de Montes Claros/UNIMONTES. Montes Claros (MG), Brasil. E-mail: anamaciel@uai.com.br

${ }^{2}$ Enfermeira. Professora Mestre do curso de Enfermagem da Universidade Estadual de Montes Claros/UNIMONTES. Montes Claros (MG), Brasil. E-mail: anamaciel@uai.com.br

${ }^{3}$ Enfermeiro. Especialista em Saúde da Família e Didática e Metodologia do Ensino Superior. Pós-Graduando em Enfermagem do Trabalho. Faculdade de Guanambi/FG. Guanambi (BA), Brasil. E-mail: patrick_mocesp70@hotmail.com

${ }^{4}$ Médico pediatra. Coordenador da UTI Neonatal do Hospital Universitário Clemente de Faria/HUCF. Montes Claros (MG), Brasil. E-mail: helderleone@ hotmail.com

${ }^{5}$ Enfermeiro. Professor Pós-Doutor Sênior do Departamento de Enfermagem da Universidade de Brasília/UNB. Brasília (DF), Brasil. E-mail: elioenai@unb.br

${ }^{6}$ Enfermeiro. Mestre em Saúde Pública. Escola Nacional de Saúde Pública/ENSP. Rio de Janeiro (RJ), Brasil. E-mail: aguiar.wilson@gmail.com
\end{abstract}

Recebido em: 0709/2015 - Aprovado em: 09/05/2016 - Disponibilizado em: 30/07/2016

\begin{abstract}
RESUMO
Objetivou-se analisar os estudos científicos que abordassem a promoção da saúde por meio da música e sintetizar os benefícios e as vantagens terapêuticas que esta produz ao ser humano. Trata-se de um estudo de natureza descritiva e exploratória, sendo uma Revisão Integrativa nas bases Cochrane, CidSaúde, Homeoindex, Ibecs, Lilacs e Medline. Foram selecionados 17 trabalhos publicados de 2004 a 2011. Foi considerado o ano de publicação, tipo de delineamento de pesquisa, caracterização da amostra, tipo de música utilizada, objetivos do estudo, procedimentos de coleta de dados e principais resultados. Os efeitos benéficos da música, como a melhora do estado emocional e da dor, alívio da ansiedade pré-operatória, diminuição da agitação e de comportamentos agressivos, melhora dos parâmetros vitais, redução de náuseas e vômitos, indução do sono, melhora nas habilidades cognitivas, sociais e físicas, modulação do humor e diversos outros benefícios que acompanham o uso da música de forma terapêutica foram encontrados em grande parte dos estudos. Considerando-se os dados encontrados ficou evidente que a música apresenta-se eficaz para a assistência de enfermagem agindo sobre todo o corpo, mas cada estilo estimula mais determinada região. Sua influência está na dependência do contexto, estilo musical e gosto do ouvinte.
\end{abstract}

Descritores: Musicoterapia. Música. Promoção da saúde.

\section{TAKING CARE WITH ART: the promotion of health through music}

\begin{abstract}
This study aimed to analyze the scientific studies that addressed health promotion through music and summarize the benefits and therapeutic benefits it produces to humans. It is a study of descriptive and exploratory nature, being an integrative Review in Cochrane base, CidSaúde, HomeoIndex, IBECS, Lilacs and Medline. We selected 17 studies published from 2004 to 2011. It was considered the year of publication, type of study design, sample characterization, type of music used, the study objectives, data collection procedures and main results. The beneficial effects of music, such as improved emotional state and pain, relieve preoperative anxiety, decreased agitation and aggressive behavior, improvement in vital parameters, reduction of nausea and vomiting, sleep induction, improvement in cognitive abilities, social and physical, mood modulation and many other benefits that come with the use of therapeutic form of music found in most studies. Considering the data found was evident that music is presented for effective nursing care acting
\end{abstract}


on the entire body, but each style encourages more particular region. His influence is depending on the context, musical style and taste of the listener.

Keywords: Music Therapy. Music. Health promotion.

\section{INTRODUÇÃO}

A música é uma arte inerente ao ser humano, é uma combinação de sons rítmicos, melódicos e harmônicos, e esta se mantém presente na vida do homem desde o seu nascimento até a sua morte, interpretando o ciclo vital ao qual está condicionado. O tempo todo, o homem escuta os sons que a natureza reproduz aos seus ouvidos, participando de celebrações, eventos sociais, inserindo-a em sua cultura e religião (HATEM; LIRA; MATTOS, 2006). Em vários rituais importantes na vida do homem em sociedade a música está tradicionalmente presente. Há músicas de ninar, músicas para festas cívicas, para rituais religiosos, para funerais, há melodias apropriadas para casamento e aniversário. A música é encontrada em todas as culturas do mundo, inclusive nas mais primitivas e desprovidas de informações tecnológicas (TABARRO et al., 2010).

Fazem parte do ser humano desde o início da vida, com o choro, os batimentos cardíacos, com a passagem de ar pela vias aéreas (PICADO; EL-KHOURI; STREAPCO, 2007). É um meio de expressar sentimentos e emoções, portanto é cabível e fundamentalmente importante introduzi-la também em nossa saúde, sendo que muitos povos, através da história, acreditavam que ela possuía um efeito terapêutico positivo, e seria também uma ponte de ligação para o estabelecimento harmônico do nosso corpo (HATEM; LIRA; MATTOS, 2006).

Desde os primórdios da humanidade a música acompanha o homem, e mesmo com o avanço da ciência a compreensão de como ela age sobre os seres humanos ainda constitui um desafio e um campo a ser pesquisado. A música abrange diversas dimensões humanas como a biológica, a emocional, a mental e a espiritual. No entanto, muitos dos caminhos pelos quais isso ocorre, ainda são pouco conhecidos, mas independente disso, sabemos que ao longo da história da humanidade e da Medicina ela é utilizada como um recurso terapêutico (LEÃO; SILVA, 2004). A música era o "remédio para a alma", segundo Platão, e como a alma se condicionava ao corpo assim como o corpo pela ginástica, o organismo humano entraria em equilíbrio e suas impurezas seriam removidas, a música pode mudar comportamentos e acelerar a cura (BRITO; FARIAS, 2005).

Pitágoras, Hipócrates e Paracelso, eram antigos pensadores que acreditavam na terapêutica utilizando música para o tratamento de doentes físicos e mentais. Séculos mais tarde, a música também era aplicada em rituais de cura por religiosos e curandeiros que acreditavam poder livrar os 
doentes dos maus espíritos que os faziam ficar doentes (BRITO; FARIAS, 2005).

Florence Nightingale foi pioneira na utilização da música como forma de humanização e cuidado à saúde em 1859. Esta foi utilizada juntamente aos soldados da I e II Guerras Mundiais (GONÇALEZ; NOGUEIRA; PUGGINA, 2008), já que a estimulação musical sobre o metabolismo cerebral produz endorfinas, que propiciam bem estar e alívio da dor (PICADO; ELKHOURI; STREAPCO, 2007). Juntamente com a radiação, a quinina e a penicilina, a música possuiu o seu lugar no leque de medicamentos do exército (CORTE; LODOVICI NETO, 2009).

O uso da música de forma terapêutica vem proporcionando resultados positivos em diversas áreas, como na saúde mental, reabilitação, educação especial e desenvolvimento social (VIANNA et al., 2011). É uma técnica de tratamento nova que se fundamenta na arte e na ciência. Foi sistematizada somente depois da Segunda Guerra Mundial, quando os primeiros resultados positivos com a sua aplicação foram registrados (PICADO; EL-KHOURI; STREAPCO, 2007).

É importante distinguir a musicoterapia e o uso da música como uma forma de cuidado. A musicoterapia é usada pelo musico terapeuta em um processo estruturado segundo um objetivo. A música como cuidado é definida com o nome de música terapêutica, sendo usada como recurso complementar no cuidado das pessoas objetivando equilíbrio, aumento da consciência do processo saúde-doença, bemestar, assim como para proporcionar conforto, para ajudar na manobra da dor, estresse ou ansiedade (SILVA et al., 2008).

$\mathrm{Na}$ atual Classificação das Intervenções de Enfermagem (CIE), a música é proposta como cuidado na assistência aos Diagnósticos de Enfermagem da North American Nursing Diagnostic Association (NANDA), como: distúrbio do sono, angústia espiritual, desesperança, ansiedade, distúrbio no campo energético, distúrbio no autoconceito, déficit de lazer, isolamento social, risco para solidão e dor (SILVA et al., 2008).

A utilização da música é um recurso a mais entre tantos outros que configuram o arsenal de intervenções da enfermagem, e que promove o cuidado biopsicossocial e espiritual e a relação do profissional com o cliente pela sua ação integrativa (SILVA et al., 2008). Portanto é importante sensibilizar os enfermeiros quanto ao uso da música na sua prática do cuidar, levando em consideração que assim como o cuidar, a música não deve ser encarada regalia de uma única profissão, mas sim de qualquer membro da equipe multiprofissional de saúde que atenda ao cliente preocupando-se em fazê-lo de maneira respeitosa, dotado de conhecimento científico e habilidades 
próprias ao afeto e à criatividade (BERGOLD; ALVIM; CABRAL, 2006).

A música é uma ferramenta que só vem a somar para a assistência de enfermagem. Considerando importante que o enfermeiro fundamente suas ações com evidências indaga-se: como as pesquisas têm contribuído para esclarecer o uso da música de forma terapêutica e as ações da enfermagem? Qual o conhecimento disponível? Quais as possíveis lacunas? Nesse intuito, este estudo poderá contribuir para a construção de novas pesquisas e para o planejamento de um cuidado de enfermagem mais humanizado. A resposta a essa questão pode colaborar para que atuações efetivas de promoção da saúde sejam realizadas. A importância desse achado poderá aprimorar a atuação do enfermeiro.

O objetivo geral deste estudo foi caracterizar os artigos científicos publicados de 2004 a 2011 que abordassem a promoção da saúde por meio da música e sintetizar os benefícios e as vantagens terapêuticas que esta produz ao ser humano.

Neste estudo pretendeu-se correlacionar a música, que vai além do simples ato de ouvir, com a saúde que nada mais é do que a harmonização do nosso corpo e mente, visto que há pouca orientação na literatura sobre o desenvolvimento de ações concretas na área da saúde com enfoque em enfermagem. Sabemos a importância dos conhecimentos acerca da temática para estruturar a elaboração de estratégias das intervenções.

\section{PERCURSO METODOLÓGICO}

Estudo exploratório, descritivo e bibliográfico, efetivado por meio de uma revisão integrativa sobre o uso da música de forma terapêutica para a promoção da saúde. A Revisão Integrativa é uma ferramenta importante no processo de comunicação dos resultados de pesquisas, facilitando sua utilização na prática clínica, visto que proporciona uma síntese do conhecimento já apresentado e fornece meios para a melhoria da assistência à saúde (MENDES; SILVEIRA; GALVÃO, 2008).

Neste estudo, investigaram-se os artigos científicos presentes em bases de dados na Biblioteca Virtual em Saúde (BVS) desde 2004 a 2011, sobre a temática em questão. As referências foram encontradas nas bases de dados: Cochrane, CidSaúde, HOMEOINDEX, IBECS, LILACS (Literatura Latino-Americana e do Caribe em Ciências da Saúde) e MEDLINE (Index Medicus). Os critérios de inclusão dos artigos consistiram em: serem escritos na língua portuguesa; apresentarem conteúdo que responda aos objetivos do estudo; publicadas no período de 2004 a 2011; disponíveis na íntegra para leitura; abordagem dos descritores estabelecidos. 
A coleta de dados procedeu de forma criteriosa por meio dos DeCS (Descritores em Ciências da Saúde) para definição das palavras chave que seriam utilizadas no estudo, sendo estabelecidos os seguintes descritores: Musicoterapia, Música, Promoção da saúde. Foi realizada no $2^{\circ}$ semestre de 2011 e $1^{\circ}$ semestre de 2012.

Após a busca dos dados as informações obtidas relacionadas aos artigos foram organizadas em gráficos e quadros e posteriormente comparadas e analisadas entre si, proporcionando conhecer claramente a produção científica sobre a temática em questão. Em um segundo momento, definiu-se nesta investigação, evidenciar o significado dos materiais textuais coletados no que concerne aos objetivos, situação na qual a música terapêutica foi utilizada, resultados e conclusões. Estes foram organizados em tópicos conforme a similaridade do conteúdo e analisados à luz da literatura publicada e com a gênese de evidências científicas.

\section{RESULTADOS E DISCUSSÃO}

Perante a análise dos objetivos dos estudos, foi possível observar a necessidade dos autores em avaliar e compreender o efeito e influências da música (Tabela 1).

Tabela 1 - Identificação dos objetivos das publicações estudadas. Montes Claros (MG), 2012.

\begin{tabular}{|c|c|c|c|c|}
\hline Autor(es) & Título & Periódico & Ano & \begin{tabular}{|c|} 
Objetivo \\
\end{tabular} \\
\hline Tabarro et al. & $\begin{array}{l}\text { Efeito da música no } \\
\text { trabalho de parto e no } \\
\text { recém-nascido }\end{array}$ & $\begin{array}{l}\text { Revista da } \\
\text { Escola de } \\
\text { Enfermagem da } \\
\text { USP }\end{array}$ & 2010 & $\begin{array}{c}\text { Verificar o efeito da música no trabalho de } \\
\text { parto e no recém-nascido, quando submetido } \\
\text { às mesmas melodias ouvidas por suas mães } \\
\text { na gestação. (n. } 15)\end{array}$ \\
\hline Zanini et al. & $\begin{array}{c}\text { O efeito da } \\
\text { musicoterapia na } \\
\text { qualidade de vida e } \\
\text { na pressão arterial do } \\
\text { paciente hipertenso }\end{array}$ & $\begin{array}{l}\text { Arquivo } \\
\text { Brasileiro de } \\
\text { Cardiologia }\end{array}$ & 2009 & $\begin{array}{c}\text { Avaliar o efeito da musicoterapia na } \\
\text { qualidade de vida (QV) e no controle da PA } \\
\text { de pacientes hipertensos. (n. 12) }\end{array}$ \\
\hline Silva et al. & $\begin{array}{l}\text { Efeito terapêutico da } \\
\text { música em portador } \\
\text { de insuficiência renal } \\
\text { crônica em } \\
\text { hemodiálise }\end{array}$ & $\begin{array}{l}\text { Revista } \\
\text { Enfermagem } \\
\text { UERJ }\end{array}$ & 2008 & $\begin{array}{l}\text { Avaliar a influência da exposição musical } \\
\text { em portadores de insuficiência renal crônica, } \\
\text { durante as sessões hemodialíticas. (n. 10) }\end{array}$ \\
\hline $\begin{array}{l}\text { Hatem, Lira, } \\
\text { Mattos }\end{array}$ & $\begin{array}{l}\text { Efeito terapêutico da } \\
\text { música em crianças } \\
\text { em pós-operatório de } \\
\text { cirurgia cardíaca }\end{array}$ & $\begin{array}{l}\text { Jornal de } \\
\text { Pediatria (Rio } \\
\text { de Janeiro) }\end{array}$ & 2006 & $\begin{array}{l}\text { Verificar de forma objetiva e subjetiva o } \\
\text { efeito da música em crianças no pós- } \\
\text { operatório de cirurgia cardíaca. (n. 06) }\end{array}$ \\
\hline Leão, Silva & $\begin{array}{l}\text { Música e dor crônica } \\
\text { músculoesquelética: o } \\
\text { potencial evocativo } \\
\text { de imagens mentais }\end{array}$ & $\begin{array}{l}\text { Revista Latino- } \\
\text { Americana de } \\
\text { Enfermagem }\end{array}$ & 2004 & $\begin{array}{c}\text { Verificar o efeito global da audição musical } \\
\text { sobre a intensidade da dor } \\
\text { musculoesquelética. (n. 01) }\end{array}$ \\
\hline
\end{tabular}

Fonte: Base de dados eletrônica - Biblioteca Virtual de Saúde (BVS). 2012.

Nas últimas décadas os efeitos que a música causa no organismo do ser humano ficam cada vez mais evidentes. Como alteração na pressão arterial, alterações nas freqüências cardíacas e respiratórias, aceleração do metabolismo, relaxamento muscular, redução de estímulos sensoriais como a dor e outros. Há relatos de alívio da 
dor crônica mediante o uso da música, algumas com relato de dez até vinte anos de sofrimento (GONÇALEZ; NOGUEIRA; PUGGINA, 2008).

No pavilhão auricular, as ondas captadas chegam ao conduto auditivo e ao tímpano, assim suas vibrações alcançam o ouvido médio sendo transformado em impulsos nervosos que se direcionam até o cérebro através do nervo vestíbulo-coclear que decifram tais estímulos como som. O movimento das vibrações sonoras nas cavidades de ressonância do cérebro e no líquido cérebro-espinhal produz um tipo de massagem sônica que, de acordo com a qualidade do som, desencadeia efeitos benéficos ou não ao sistema biopsicoenergético. As fibras nervosas transformam o som capturado em estímulo nervoso (SILVA et al., 2008).

Outro foco de atenção dos artigos foi a necessidade de caracterizar e analisar a produção bibliográfica da enfermagem que aborde o uso da música em sua assistência (Tabela 2).

Tabela 2 - Identificação dos objetivos das publicações estudadas. Montes Claros (MG), 2012.

\begin{tabular}{|c|c|c|c|c|}
\hline Autor(es) & Título & Periódico & Ano & Objetivo \\
\hline $\begin{array}{c}\text { Ferreira, } \\
\text { Remedi, Lima }\end{array}$ & $\begin{array}{l}\text { A música como } \\
\text { recurso no } \\
\text { cuidado à criança } \\
\text { hospitalizada: } \\
\text { uma intervenção } \\
\text { possível? }\end{array}$ & $\begin{array}{l}\text { Revista } \\
\text { Brasileira de } \\
\text { Enfermagem }\end{array}$ & 2006 & $\begin{array}{l}\text { Analisar a produção bibliográfica da } \\
\text { enfermagem pediátrica quanto à utilização da } \\
\text { música como recurso terapêutico no espaço } \\
\text { hospitalar. (n. } 04 \text { ) }\end{array}$ \\
\hline $\begin{array}{l}\text { Gonçalez, } \\
\text { Nogueira, } \\
\text { Puggina }\end{array}$ & $\begin{array}{l}\text { O uso da música } \\
\text { na assistência de } \\
\text { enfermagem no } \\
\text { Brasil: uma } \\
\text { revisão } \\
\text { bibliográfica }\end{array}$ & $\begin{array}{c}\text { Cogitare } \\
\text { Enfermagem }\end{array}$ & 2008 & $\begin{array}{l}\text { Caracterizar os estudos publicados em âmbito } \\
\text { nacional que abordem o uso da música na } \\
\text { assistência de enfermagem. (n. 08) }\end{array}$ \\
\hline $\begin{array}{l}\text { Andrade, } \\
\text { Pedrão }\end{array}$ & $\begin{array}{c}\text { Algumas } \\
\text { considerações } \\
\text { sobre a utilização } \\
\text { de modalidades } \\
\text { terapêuticas não } \\
\text { tradicionais pelo } \\
\text { enfermeiro na } \\
\text { assistência de } \\
\text { enfermagem } \\
\text { psiquiátrica }\end{array}$ & $\begin{array}{l}\text { Revista Latino- } \\
\text { Americana de } \\
\text { Enfermagem }\end{array}$ & 2005 & $\begin{array}{c}\text { Identificar trabalhos que descrevessem } \\
\text { modalidades terapêuticas não tradicionais que } \\
\text { o enfermeiro psiquiátrico tem capacidade para } \\
\text { utilizar em sua prática diária. (n. 02) }\end{array}$ \\
\hline
\end{tabular}

Diversas pesquisas na área da enfermagem vêm usando a música terapêutica com o intuito de sensibilizar os enfermeiros à sua utilização tanto como estratégia de cuidado quanto de ensino aos clientes que por sua vez, estejam vivenciando diversas situações no campo do contexto hospitalar (BERGOLD; ALVIM, 2009). A música pode ser utilizada pelo enfermeiro no tratamento de pacientes em diferentes momentos e com diversos propósitos, como para relaxar, em confraternizações ou mesmo resgatar 
lembranças de acontecimentos passados. E como o enfermeiro está mais próximo do paciente por acompanhar sua evolução, este deve analisar em que momento a música será usada e avaliar os seus efeitos sobre o paciente

(GONÇALEZ;

NOGUEIRA;

PUGGINA, 2008).

Alguns dos artigos objetivaram analisar a percepção dos profissionais musicoterapeutas ou músicos sobre a atividade musical em seus clientes (Tabela 3).

Tabela 3 - Identificação dos objetivos das publicações estudadas. Montes Claros (MG), 2012.

\begin{tabular}{|c|c|c|c|c|}
\hline Autor(es) & Título & Periódico & Ano & Objetivo \\
\hline Leão, Flusser & $\begin{array}{l}\text { Música para idosos } \\
\text { institucionalizados: } \\
\text { percepção dos } \\
\text { músicos atuantes }\end{array}$ & $\begin{array}{c}\text { Revista da } \\
\text { Escola de } \\
\text { Enfermagem da } \\
\text { USP }\end{array}$ & 2008 & $\begin{array}{c}\text { Analisar a percepção dos músicos sobre a } \\
\text { atividade musical junto a idosos } \\
\text { institucionalizados. (n. 09) }\end{array}$ \\
\hline Fonseca et al. & $\begin{array}{l}\text { Credibilidade e } \\
\text { efeitos da música } \\
\text { como modalidade } \\
\text { terapêutica em } \\
\text { saúde }\end{array}$ & $\begin{array}{l}\text { Revista } \\
\text { Eletrônica de } \\
\text { Enfermagem }\end{array}$ & 2006 & $\begin{array}{c}\text { Analisar a percepção dos profissionais } \\
\text { musicoterapeutas sobre a credibilidade e } \\
\text { aceitação da musicoterapia por seus clientes. } \\
\text { (n. 05) }\end{array}$ \\
\hline
\end{tabular}

Fonte: Base de dados eletrônica - Biblioteca Virtual de Saúde (BVS). 2012.

A intervenção através da música pode refletir na instituição de saúde de maneira positiva, acarretando a instauração de um ambiente terapêutico, no qual o cliente se sente valorizado em dimensões que eventualmente não são abordadas no sistema convencional de saúde. A grande parte dos usuários dos serviços de saúde é favorável à utilização da terapêutica com música. Muitos dos profissionais relatam que a existência desse ambiente é importante para o cuidado humanizado em saúde e para o estabelecimento de vínculos de confiança entre $\mathrm{o}$ cliente, $\mathrm{o}$ profissional $\mathrm{e}$ consequentemente com a instituição de saúde (FONSECA et al., 2006).

Também houve interesse em pesquisar as contribuições que a música oferece para a prática do cuidado da pessoa que não tem possibilidade de cura (Tabela 4).
A música pode aliviar o desconforto e ansiedade de pacientes que experienciam a terminalidade, assim como promover um ambiente mais prazeroso aos familiares que participam do cuidado. A música também alegra o ouvinte e é, normalmente, preferível ao silêncio, em especial para pessoas com dores, pois o silêncio pode aumentar sua consciência do desconforto. A música suave, de fundo, proporciona o alívio da ansiedade e estresse, por capacitar a sintonia ou harmonia com o ambiente. Esse encontro revela como ondas cerebrais, tom emocional, frequência cardíaca, respiração e diversos ritmos orgânicos podem mudar de acordo com o que se ouve (SILVA et al., 2008). O coração assume as pulsações segundo o ritmo da música, os ritmos saudáveis e harmoniosos agem como sedativos eficazes, pois estimulam o hipotálamo a liberar endorfinas, 
que são muito mais benéficas em um longo período do que substâncias tóxicas que podem desencadear dependência (BRITO; FARIAS, 2005). Um artigo objetivou discutir a contribuição que a música oferece para o desenvolvimento de tecnologias voltadas para o cuidado da enfermagem.

Tabela 4 - Identificação dos objetivos das publicações estudadas. Montes Claros (MG), 2012.

\begin{tabular}{|c|c|c|c|c|}
\hline Autor(es) & Título & Periódico & Ano & Objetivo \\
\hline Seki, Galheigo & $\begin{array}{l}\text { O uso da música } \\
\text { nos cuidados } \\
\text { paliativos: } \\
\text { humanizando o } \\
\text { cuidado e } \\
\text { facilitando o } \\
\text { adeus }\end{array}$ & $\begin{array}{l}\text { Interface - } \\
\text { Comunicação, } \\
\text { Saúde \& } \\
\text { Educação }\end{array}$ & 2010 & $\begin{array}{l}\text { Refletir sobre as contribuições do uso da } \\
\text { música nos cuidados paliativos e na } \\
\text { humanização do cuidado da pessoa fora de } \\
\text { possibilidades terapêuticas de cura. (n. 14) }\end{array}$ \\
\hline Sales et al. & $\begin{array}{l}\text { A música na } \\
\text { terminalidade } \\
\text { humana: } \\
\text { concepções dos } \\
\text { familiares }\end{array}$ & $\begin{array}{l}\text { Revista da } \\
\text { Escola de } \\
\text { Enfermagem da } \\
\text { USP }\end{array}$ & 2011 & $\begin{array}{l}\text { Compreender como os familiares percebem a } \\
\text { influência das vivências musicais na saúde } \\
\text { física e mental de um familiar que experiência } \\
\text { a terminalidade. (n. 17) }\end{array}$ \\
\hline Bergold, Alvim & $\begin{array}{c}\text { A música } \\
\text { terapêutica como } \\
\text { uma tecnologia } \\
\text { aplicada ao } \\
\text { cuidado e ao } \\
\text { ensino de } \\
\text { enfermagem }\end{array}$ & $\begin{array}{c}\text { Escola Anna } \\
\text { Nery }\end{array}$ & 2009 & $\begin{array}{c}\text { O foco da discussão é a contribuição da } \\
\text { musicoterapia ao desenvolvimento de } \\
\text { tecnologias aplicadas ao cuidado e ao ensino } \\
\text { de enfermagem. (n. 11) }\end{array}$ \\
\hline
\end{tabular}

Fonte: Base de dados eletrônica - Biblioteca Virtual de Saúde (BVS). 2012.

Os artigos abordaram em sua temática os efeitos e benefícios que a música terapêutica oferece aos clientes, assim como demonstraram a importância deste recurso como um instrumento a mais que o enfermeiro pode lançar mão a fim de promover um cuidado mais humanizado.

Toda fração do corpo humano acusa a influência dos sons musicais, a música age de maneira direta sobre as células e órgãos que o constituem e de forma indireta mobilizando as emoções e influenciando positivamente em numerosos processos corporais que acarretam relaxamento e bem-estar (GONÇALEZ; NOGUEIRA; PUGGINA, 2008). Assim, há uma necessidade urgente de buscar, desenvolver, testar e traduzir as intervenções baseadas em evidências que utilizam a música de forma terapêutica.

\section{Situação na qual ocorreu a abordagem do uso da música terapêutica}

Os autores dos artigos n. 02, n. 04, n. 07 , n. 08, n. 13 , n. 14 , n. 16 optaram por realizar uma revisão de literatura acerca da temática, sendo que o primeiro artigo identificou os trabalhos que descrevem modalidades terapêuticas não tradicionais que o enfermeiro psiquiátrico tem possibilidade de usar em sua prática diária. O artigo n.04 analisou a produção bibliográfica da enfermagem pediátrica quanto à utilização da música como recurso terapêutico no espaço 
hospitalar, a fim de identificar o estado do conhecimento desta área nesse campo. O artigo n. 07 optou por analisar publicações que demonstrem o efeito da música para o corpo e mente. $\mathrm{O}$ artigo n. 08 investigou o uso da música na assistência de enfermagem no Brasil. A publicação n. 13 deu enfoque ao uso da música para propiciar analgesia. $\mathrm{O}$ artigo n. 14 abordou o uso da música nos cuidados paliativos a fim de humanizar o cuidado e facilitar o adeus. $\mathrm{O}$ artigo n. 16 investigou a intervenção da música no ambiente de terapia intensiva neonatal

$\mathrm{Na}$ publicação n. 1 os dados foram obtidos por meio de entrevista onde noventa mulheres com diagnósticos de fibromialgia, lesão por esforços repetitivos/doenças osteoarticulares, relacionadas ao trabalho (LER/DORT), e afecções relacionadas à coluna vertebral foram submetidas à audição individual de três peças musicais. A intensidade da dor foi avaliada pela escala numérica verbal $(0-10)$ antes e ao término da audição musical, sendo aplicada em ambiente ambulatorial.

Para analisar os dados os artigos n. 03, n. 09, n. 11 optaram pela análise de discurso, uma vez que esta trabalha com os processos de constituição dos sujeitos e dos sentidos. Os sujeitos da pesquisa do artigo n. 03 foram sete enfermeiros de ambos os sexos e idades variadas, apresentando prática profissional em diferentes áreas: assistencial, administrativa, ensino e pesquisa. $\mathrm{O}$ estudo do artigo n. 09 foi realizado com oito músicos que atuavam há mais de um ano em Instituições de Longa Permanência, foi utilizado o método do Discurso do Sujeito Coletivo (DSC) que busca resgatar o discurso coletivo a partir dos discursos individuais. No artigo n. 11 a pesquisa foi realizada com 14 clientes de ambos os sexos e idades variadas hospitalizados em um hospital militar da cidade do Rio de Janeiro e contou também com 11 enfermeiros de ambos os sexos e idades variadas, alunos de uma disciplina de pós-graduação da Escola de Enfermagem Anna Nery/UFRJ.

Também houve a realização da coleta de dados por meio da entrevista gravada, artigo n. 05 , n. 10 , n. 15, n. 17. No primeiro estudo a entrevista foi direcionada por um roteiro com questões abertas referentes à temática em estudo. Onde participaram do estudo 15 musicoterapeutas. Os locais selecionados para a realização do estudo incluem quatro hospitais da rede pública de saúde. No artigo n. 10, realizou-se uma pergunta norteadora onde 35 sujeitos que realizavam hemodiálise em uma sala de ambulatório participaram da pesquisa. No artigo n. 15, 27 gestantes participaram do estudo incluindo também os recém-nascidos na pesquisa que se iniciou nas Unidades Básicas de Saúde, domicílio e se estendeu para o ambiente hospitalar. Os discursos obtidos nas entrevistas foram registrados em fita cassete, transcritos na íntegra e analisados 
à luz da proposta dos autores. Para a coleta de dados do artigo n. 17 foram utilizadas duas técnicas: entrevista com uma questão aberta gravada e a observação. Esses dados foram coletados junto a sete indivíduos pertencentes a duas famílias que residiam na área de abrangência de uma Unidade Básica de Saúde onde ocorriam visitas ao domicílio dos sujeitos pesquisados.

Na publicação n. 06 a coleta de dados foi obtida através de variáveis, se deu por meio de formulário próprio, preenchido pelo(a) auxiliar de enfermagem responsável por acompanhar a criança. Participaram do estudo 84 crianças em pós-operatório de cirurgia cardíaca em um ambiente hospitalar. $\mathrm{O}$ artigo n. 12 também avaliou variáveis de pacientes hipertensos e maiores de 50 anos.

As variáveis mais comumente utilizadas nos estudos realizados para testar o efeito da intervenção com música foram variáveis fisiológicas ou comportamentais, por exemplo, a frequência cardíaca, saturação de oxigênio e diferentes escalas de comportamento, com ou sem estímulos externos (por exemplo, dor)

\section{Características e efeitos dos estilos musicais} abordados nas publicações

Nos estudos foram utilizados vários estilos musicais, no entanto, o estilo predominante foi $\mathrm{o}$ da música clássica algumas vezes sozinha, outras, junto com chorinho e rock ou música em geral como popular ou sertaneja. Também foram utilizadas canções de ninar.

A primeira música abordada no estudo em um dos estudos científicos foi do tipo clássico, com características mais melódicas e harmoniosas e de pouca ênfase no ritmo, sendo relaxante por seu andamento lento (BERGOLD; ALVIM; CABRAL, 2006).

De acordo com a percepção de parâmetros de andamento e modo dependerá a resposta emocional provocada pela música. $\mathrm{O}$ modo é definido por uma série de notas sucessivas que são organizadas de acordo com um padrão de intervalos definido, o que difere um padrão de um modo a outro é por ser maior ou menor. $\mathrm{O}$ que define o andamento é o grau de velocidade que se imprime à execução de um trecho musical. Assim as músicas do tipo lento e modo maior podem induzir à serenidade. Outro parâmetro situa-se na música tranqüilizante que está relacionada a tempos regulares e harmonia. Já as músicas que comportam disparidades de ritmo e dissonâncias, como acordes que geram forte tensão, tornando-se instáveis para o ouvinte, seriam mais estressantes (BERGOLD; ALVIM; CABRAL, 2006).

A influência da música clássica se fez presente na totalidade do corpo dos participantes, contudo em maior concentração na região da cabeça e do tórax. Alguns efeitos descritos pelos participantes foram suavidade, choro, riso, canto, tranqüilidade. Foram 
discriminadas também a narina, a boca e a mão, integrando outros sentidos nessa percepção musical. Houve dois participantes que relacionaram a palavra "dança" às pernas, pois apesar de relaxante, a música clássica também impelia a movimentos de dança (BERGOLD; ALVIM; CABRAL, 2006).

Outra música abordada foi o chorinho, com a predominância do som do saxofone que dá um toque de sensualidade à melodia, acompanhada por violão, baixo e piano, apresentando o ritmo marcado executado por uma bateria.

As pessoas mostraram-se mais descontraídas e sorridentes durante a audição do chorinho, executado movimento corporais como balançar o corpo e batucar com as mãos. O chorinho fazia parte do universo musical de quase todos os participantes, interligando-os a sentimentos positivos, conectados à sensação de prazer e diversão (BERGOLD; ALVIM; CABRAL, 2006).

A qualidade integradora da música e suas possibilidades lúdicas também foram demonstradas na discussão grupal com clientes internados, onde foi abordada a atividade musical na promoção da comunicação e da interação no ambiente hospitalar (BERGOLD; ALVIM; CABRAL, 2006).

Outro estilo utilizado foi o rock, por ser um estilo que contrasta com os anteriores, criando um impacto. Foi usado um rock mais "pesado", com ritmo pronunciado, guitarras distorcidas e vozes gritadas. Alguns participantes riram logo no início da execução da música considerando engraçado esse tipo de música naquele contexto. No entanto, foi constatado durante a discussão grupal que o rock trouxe desconforto para a maioria dos participantes e os fez associar este estímulo a movimentos mecânicos do corpo (BERGOLD; ALVIM; CABRAL, 2006).

Em diversos estudos o estilo musical escolhido foi definido pelo profissional juntamente com os clientes, que optavam por músicas conhecidas, as quais traziam recordações do passado, a sensação de bemestar e conforto. Também houve o uso de canções de ninar em um estudo que tinha por objetivo analisar o impacto da musica nos índices de aleitamento materno entre mães de neonatos prematuros (Tabela 5).

Tabela 5 - Características e efeitos dos estilos musicais abordados nas publicações. Montes Claros (MG), 2012.

\begin{tabular}{|c|c|c|c|c|}
\hline Autor(es) & Título & Periódico & Ano & Características e efeitos dos estilos musicais \\
\hline $\begin{array}{c}\text { Bergold, Alvim, } \\
\text { Cabral }\end{array}$ & $\begin{array}{l}\text { O lugar da música } \\
\text { no espaço do } \\
\text { cuidado } \\
\text { terapêutico: } \\
\text { sensibilizando } \\
\text { enfermeiros com a } \\
\text { dinâmica musical }\end{array}$ & $\begin{array}{c}\text { Texto \& } \\
\text { Contexto - } \\
\text { Enfermagem }\end{array}$ & 2006 & $\begin{array}{l}\text { A música escolhida foi descrita por todos os } \\
\text { participantes como relaxante, sendo observado } \\
\text { que os que inicialmente tiveram dificuldade } \\
\text { para relaxar durante a indução verbal } \\
\text { demonstraram relaxar ao escutá-la. (n. 03) }\end{array}$ \\
\hline Bergold, Alvim, & O lugar da música & Texto \& & 2006 & Esse momento lúdico estimulou a comunicação \\
\hline
\end{tabular}




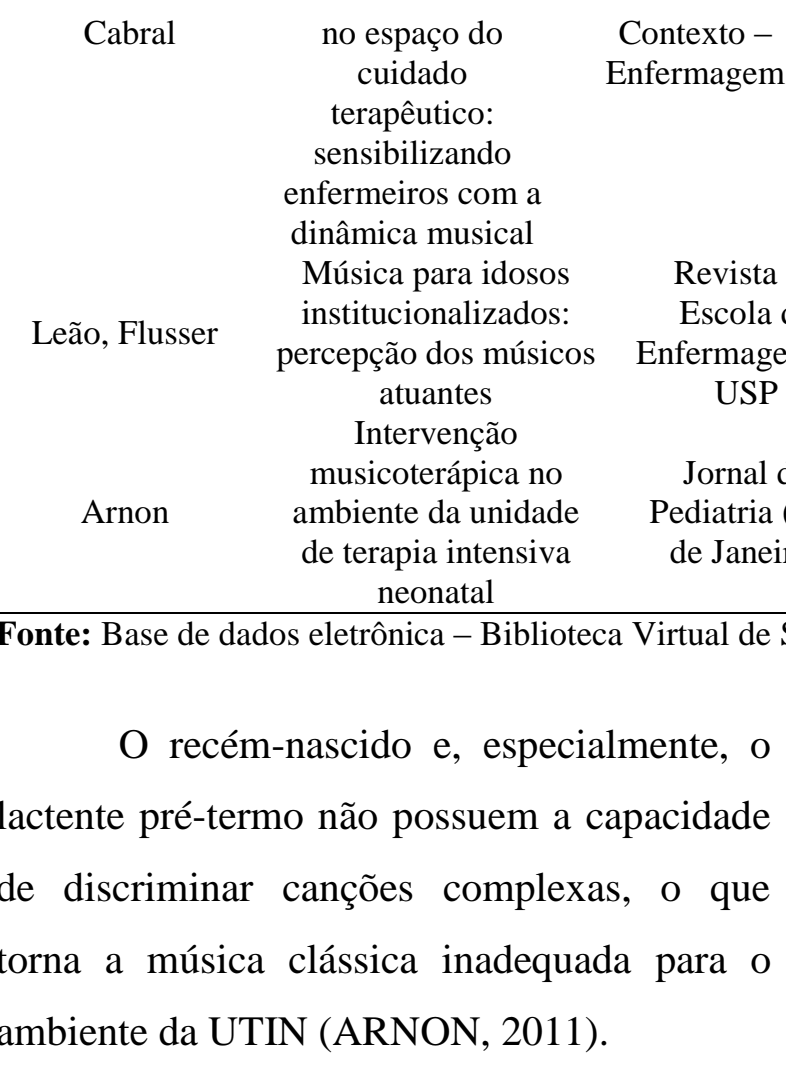

\section{Resultados apresentados nas publicações} estudadas

Para facilitar a análise e compreensão dos resultados das publicações selecionadas, serão apresentados de acordo com a situação em que ocorreu a abordagem do uso da música terapêutica.

\section{Abordagem do uso da música terapêutica na revisão de literatura}

Os artigos que revisaram a literatura acerca do uso da música de forma terapêutica proporcionaram evidenciar que a mesma é um recurso eficaz em sua assistência e que o enfermeiro pode utilizar a música com vários propósitos e em diferentes momentos do tratamento do cliente. A criança hospitalizada entre os participantes, levando-os a trocar olhares ou rápidos comentários, apontando a possibilidade de integração promovida pela música. (n. 03)

Tudo depende da pessoa, do estado da pessoa (desperta, cansado, queixoso, melancólico...). Para a escolha de repertório. (n. 09)

Canções de ninar são estruturas musicais simples que os lactentes podem diferenciar claramente e são caracterizadas por um tom mais baixo e um ritmo mais lento, usados e reconhecidos em várias culturas. (n. 16)
2011

2008 (BVS). 2012. também foi foco da discussão sobre os benefícios que a música pode proporcionar, uma vez que a mesma enfrenta dificuldades de adaptação, estresse e ansiedade quando inserida em ambiente hospitalar. A música terapêutica foi introduzida na UTIN a fim de melhorar o tratamento e facilitar o crescimento e desenvolvimento de lactentes prematuros. Avaliando assim, a eficácia da terapia para lactentes prematuros $\mathrm{e}$ demonstrando os seus benefícios (Tabela 6).

A música também é benéfica em casos de demência, causados comumente pela doença de Alzheimer, pois a pessoa com Alzheimer sofre perda da memória, podendo progredir para a amnésia profunda, e de várias outras habilidades, como a fala e a autopercepção. No entanto, mesmo que a demência seja muito severa, aspectos de sua personalidade podem sobreviver, em especial a resposta à música. Esse controle é possível devido à persistência de habilidades relacionadas à música, mesmo um longo período após o qual outras formas de memória tenham desaparecido. Seus efeitos podem 
persistir por horas ou dias, registrando-se

função cognitiva (SEKI; GALHEIGO, 2010).

melhora do humor comportamento e, até, da

Tabela 6 - Identificação dos resultados abordados nas publicações. Montes Claros (MG), 2012.

\begin{tabular}{|c|c|c|c|c|}
\hline Autor(es) & Título & Periódico & Ano & Resultados \\
\hline $\begin{array}{l}\text { Andrade, } \\
\text { Pedrão }\end{array}$ & $\begin{array}{c}\text { Algumas } \\
\text { considerações } \\
\text { sobre a utilização } \\
\text { de modalidades } \\
\text { terapêuticas não } \\
\text { tradicionais pelo } \\
\text { enfermeiro na } \\
\text { assistência de } \\
\text { enfermagem } \\
\text { psiquiátrica }\end{array}$ & $\begin{array}{l}\text { Revista Latino- } \\
\text { Americana de } \\
\text { Enfermagem }\end{array}$ & 2005 & $\begin{array}{l}\text { Antes da interação com o mesmo, para } \\
\text { relaxamento, para resgatar lembranças de } \\
\text { acontecimentos passados na vida do cliente. } \\
\text { Cabe ao enfermeiro verificar em que momento } \\
\text { ele pode utilizar essa prática e também avaliar } \\
\text { os efeitos da música sobre o paciente. (n. 02) }\end{array}$ \\
\hline $\begin{array}{l}\text { Gonçalez, } \\
\text { Nogueira, } \\
\text { Puggina }\end{array}$ & $\begin{array}{l}\text { O uso da música } \\
\text { na assistência de } \\
\text { enfermagem no } \\
\text { Brasil: uma } \\
\text { revisão } \\
\text { bibliográfica }\end{array}$ & $\begin{array}{c}\text { Cogitare } \\
\text { Enfermagem }\end{array}$ & 2008 & $\begin{array}{l}\text { Os principais resultados apontaram que a } \\
\text { maioria dos estudos, } 11 \text { dos } 12 \text { demonstraram } \\
\text { que a música pode ser eficaz na assistência de } \\
\text { enfermagem, e faz aflorar sentimentos que } \\
\text { permanecem escondidos. (n. 08) }\end{array}$ \\
\hline $\begin{array}{c}\text { Ferreira, } \\
\text { Remedi, Lima }\end{array}$ & $\begin{array}{l}\text { A música como } \\
\text { recurso no } \\
\text { cuidado à criança } \\
\text { hospitalizada: } \\
\text { uma intervenção } \\
\text { possível? }\end{array}$ & $\begin{array}{c}\text { Revista } \\
\text { Brasileira de } \\
\text { Enfermagem }\end{array}$ & 2006 & $\begin{array}{l}\text { A intervenção musical durante a assistência à } \\
\text { criança hospitalizada possibilita que esta } \\
\text { verbalize seus estresses e ansiedades e a partir } \\
\text { daí desenvolva estratégias de enfrentamento } \\
\text { para as suas dificuldades. (n. 04) }\end{array}$ \\
\hline Todres & $\begin{array}{l}\text { Música é remédio } \\
\text { para o coração }\end{array}$ & $\begin{array}{c}\text { Jornal de } \\
\text { Pediatria (Rio } \\
\text { de Janeiro) }\end{array}$ & 2006 & $\begin{array}{l}\text { A dor pós-operatória pode exacerbar o estresse } \\
\text { da criança e complicar a evolução pós- } \\
\text { operatória, e a contribuição da música para o } \\
\text { controle da dor e da ansiedade, que são } \\
\text { freqüentemente inter-relacionadas, pode } \\
\text { propiciar uma melhor evolução pós-operatória. } \\
\text { (n. 07) }\end{array}$ \\
\hline Arnon & $\begin{array}{l}\text { Intervenção } \\
\text { musicoterápica no } \\
\text { ambiente da } \\
\text { unidade de terapia } \\
\text { intensiva neonatal }\end{array}$ & $\begin{array}{c}\text { Jornal de } \\
\text { Pediatria (Rio } \\
\text { de Janeiro) }\end{array}$ & 2011 & $\begin{array}{l}\text { Os benefícios mais evidentes foram ganho de } \\
\text { peso, redução dos comportamentos de estresse } \\
\text { e do tempo de hospitalização, e níveis elevados } \\
\text { de saturação de oxigênio por curtos períodos } \\
\text { de tempo. (n. 16) }\end{array}$ \\
\hline Seki, Galheigo & $\begin{array}{l}\text { O uso da música } \\
\text { nos cuidados } \\
\text { paliativos: } \\
\text { humanizando o } \\
\text { cuidado e } \\
\text { facilitando o } \\
\text { adeus }\end{array}$ & $\begin{array}{l}\text { Interface - } \\
\text { Comunicação, } \\
\text { Saúde \& } \\
\text { Educação }\end{array}$ & 2010 & $\begin{array}{c}\text { Esta pode atingir e estimular esse self } \\
\text { sobrevivente, as emoções, as faculdades } \\
\text { cognitivas, os pensamentos e as memórias. A } \\
\text { musicoterapia pode ser utilizada para } \\
\text { "enriquecer e ampliar a existência, dar } \\
\text { liberdade, estabilidade, organização e foco". } \\
\text { (n. 14) }\end{array}$ \\
\hline
\end{tabular}

Fonte: Base de dados eletrônica - Biblioteca Virtual de Saúde (BVS). 2012.

Durante a internação hospitalar

Três estudos foram realizados em ambiente hospitalar (artigos n. 05, n. 06 e n. 11), tendo sido explorado tanto os efeitos e benefícios do uso da música ao cliente como sua credibilidade quanto à terapia desenvolvida (Tabela 7).

A utilização de música no ambiente hospitalar aumenta constantemente, inúmeras pesquisas já comprovavam os seus benefícios, por isso deve-se acrescentar a este acervo 
novos estudos que contribuam para o nosso conhecimento específico, mesmo que de forma alguma alcancemos como um todo esse infinito universo musical. O tempo todo se ouve falar de um cuidado mais humanizado tanto ao indivíduo que se encontra debilitado em um leito de hospital como para aquele que ainda não desenvolveu uma enfermidade, pesquisas descobrem todos os dias novos medicamentos capazes de tratar diversas enfermidades, novas máquinas surgem em uma rapidez acelerada pela tecnologia, informações percorrem o mundo em poucos segundos com a globalização estacionada à nossa porta, portanto é relevante encontrar o potencial que a música também é capaz de proporcionar ao homem, com suas harmonias, ritmos, melodias, atingindo assim o completo bem estar que é traduzido em saúde.
Os profissionais que desenvolvem a terapêutica por meio da música relatam efeitos interessantes sobre essa forma de amenizar ou aliviar problemas de saúde (Tabela 7).

Há inúmeras experiências na área da saúde, assim como diversos trabalhos que utilizam a música como elemento importante para o controle da ansiedade dos pacientes, sendo cada vez mais comum a presença da música nestes locais, contribuindo para diminuir a sensação de dor em pacientes póscirúrgicos, estimulando as contrações de mulheres em trabalho de parto ou mesmo na estimulação de pacientes com dano cerebral. Desta forma, não é um exagero afirmar que "os efeitos da música sobre os sentimentos humanos estão, cada vez mais, migrando da sabedoria popular para o reconhecimento científico" (NOGUEIRA, 2003).

Tabela 7 - Identificação dos resultados abordados nas publicações. Montes Claros (MG), 2012.

\begin{tabular}{|c|c|c|c|c|}
\hline Autor(es) & Título & Periódico & Ano & Resultados \\
\hline Bergold, Alvim & $\begin{array}{c}\text { A música } \\
\text { terapêutica como } \\
\text { uma tecnologia } \\
\text { aplicada ao } \\
\text { cuidado e ao } \\
\text { ensino de } \\
\text { enfermagem }\end{array}$ & $\begin{array}{c}\text { Escola Anna } \\
\text { Nery }\end{array}$ & 2009 & $\begin{array}{l}\text { O uso da música terapêutica como um recurso } \\
\text { para o cuidado ao cliente hospitalizado } \\
\text { potencializou sua restauração por meio do } \\
\text { conforto, bem-estar, expressão das emoções e } \\
\text { compartilhamento de experiências, além de } \\
\text { promover sua autonomia pela sua escolha no } \\
\text { momento do cuidado. Possibilitou também } \\
\text { interação entre os clientes e destes com a } \\
\text { equipe de saúde, promovendo a humanização } \\
\text { hospitalar. (n. 11). }\end{array}$ \\
\hline $\begin{array}{c}\text { Hatem, Lira, } \\
\text { Mattos }\end{array}$ & $\begin{array}{l}\text { Efeito terapêutico } \\
\text { da música em } \\
\text { crianças em pós- } \\
\text { operatório de } \\
\text { cirurgia cardíaca } \\
\text { O efeito da }\end{array}$ & $\begin{array}{c}\text { Jornal de } \\
\text { Pediatria (Rio } \\
\text { de Janeiro) }\end{array}$ & 2006 & $\begin{array}{l}\text { Após a intervenção, houve diferença } \\
\text { significante entre os grupos, com menores FC } \\
\text { e FR para as crianças com musicoterapia } \\
\text { quando comparadas com as sem musicoterapia. } \\
\text { (n. 06) }\end{array}$ \\
\hline Zanini et al. & $\begin{array}{l}\text { musicoterapia na } \\
\text { qualidade de vida } \\
\text { e na pressão } \\
\text { arterial do } \\
\text { paciente } \\
\text { hipertenso }\end{array}$ & $\begin{array}{l}\text { Arquivo } \\
\text { Brasileiro de } \\
\text { Cardiologia }\end{array}$ & 2009 & $\begin{array}{l}\text { Os resultados demonstraram a melhora dos } \\
\text { níveis de estresse, da satisfação pessoal, do } \\
\text { consumo de alimentos ricos em fibras e maior } \\
\text { motivação para o viver. (n. 12) }\end{array}$ \\
\hline
\end{tabular}


Credibilidade e efeitos da música

Fonseca et al. como modalidade terapêutica em saúde
Revista

Eletrônica de

Enfermagem
2006

Demonstram inclusive, a credibilidade pessoal nesta terapia ao afirmarem que membros da própria família também são usuários. (n. 05)

Fonte: Base de dados eletrônica - Biblioteca Virtual de Saúde (BVS). 2012.

\section{No ambulatório}

Os estudos realizados em ambulatórios abordaram o uso da música no tratamento das doenças crônicas. $\mathrm{O}$ artigo n. 01 analisou os efeitos da música na dor crônica musculoesquelética enquanto o artigo n. 10 verificou o efeito terapêutico da música em portadores de insuficiência renal crônica em hemodiálise (Tabela 8).

Vários são os mecanismos que se relacionam com o alívio da dor, dentre os quais estão a distração, a alteração do foco perceptual, a liberação de endorfinas e o relaxamento. Assim, a música permite escape temporário para "um mundo sem dor" (LEÃO; SILVA, 2004). Com a utilização da música, a angústia em relação à espera pelo final da sessão se torna menor, pois o foco de atenção no tempo é desviado. Os sons também podem acalmar, deixar o paciente sossegado e induzir ao sono (SILVA et al., 2008).

Tabela 8 - Identificação dos resultados abordados nas publicações. Montes Claros (MG), 2012.

\begin{tabular}{|c|c|c|c|c|}
\hline Autor(es) & Título & Periódico & Ano & $\begin{array}{l}\text { Resultados } \\
\end{array}$ \\
\hline Leão, Silva & $\begin{array}{l}\text { Música e dor crônica } \\
\text { músculoesquelética: o } \\
\text { potencial evocativo de } \\
\text { imagens mentais }\end{array}$ & $\begin{array}{l}\text { Revista Latino- } \\
\text { Americana de } \\
\text { Enfermagem }\end{array}$ & 2004 & $\begin{array}{l}\text { A audição musical, neste estudo, levou à } \\
\text { redução estatisticamente significativa da } \\
\text { dor para o global das pacientes, resultado } \\
\text { esse corroborado por outros autores no } \\
\text { alívio de outras dores crônicas. (n. 01) }\end{array}$ \\
\hline Silva et al. & $\begin{array}{l}\text { Efeito terapêutico da } \\
\text { música em portador de } \\
\text { insuficiência renal } \\
\text { crônica em hemodiálise }\end{array}$ & $\begin{array}{c}\text { Revista } \\
\text { Enfermagem } \\
\text { UERJ }\end{array}$ & 2008 & $\begin{array}{l}\text { Na análise temática dos discursos dos } \\
\text { sujeitos foram identificadas cinco } \\
\text { categorias: alteração positiva da percepção } \\
\text { do tempo; bem-estar, entretenimento e } \\
\text { mudança na rotina, recordações positivas e } \\
\text { companhia. (n. 10) }\end{array}$ \\
\hline
\end{tabular}

Fonte: Base de dados eletrônica - Biblioteca Virtual de Saúde (BVS). 2012.

\section{Na Universidade}

Somente o estudo do artigo n. 11 foi realizado em um ambiente de ensino, sendo discutido o uso da música no cuidado e no ensino da enfermagem (Tabela 9).
A música também facilita o desenvolvimento de habilidades de aprendizagem, padrões e processos de pensamento, nível de conhecimento, atitudes, estilo cognitivo de crenças. O que aponta sua importância com recurso tecnológico para o ensino-aprendizagem do enfermeiro, tanto 
quanto em ação educativa junto ao cliente

(BERGOLD; ALVIM, 2009).

Tabela 9 - Identificação dos resultados abordados nas publicações. Montes Claros (MG), 2012.

\begin{tabular}{|c|c|c|c|c|}
\hline Autor(es) & Título & Periódico & Ano & Resultados \\
\hline Bergold, Alvim & $\begin{array}{l}\text { A música } \\
\text { terapêutica como } \\
\text { uma tecnologia } \\
\text { aplicada ao } \\
\text { cuidado e ao } \\
\text { ensino de } \\
\text { enfermagem }\end{array}$ & $\begin{array}{c}\text { Escola Anna } \\
\text { Nery }\end{array}$ & 2009 & $\begin{array}{l}\text { Quanto ao potencial da música para o ensino, } \\
\text { os participantes apontaram o uso da música } \\
\text { clássica para estudar, pois influencia a atenção, } \\
\text { a memória, o desenvolvimento do pensamento } \\
\text { lógico, a criatividade e a maturação intelectual, } \\
\text { a percepção, emoção e racionalidade, e pode } \\
\text { ser estimulada por uma experiência musical } \\
\text { com o intuito de desenvolver a sensibilidade. }\end{array}$ \\
\hline
\end{tabular}

Fonte: Base de dados eletrônica - Biblioteca Virtual de Saúde (BVS). 2012.

\section{No domicílio}

As investigações dos artigos n. 15 e $n$. 17 aconteceram no âmbito domiciliar, sendo que a abordagem ao uso da música aconteceu de forma distinta, o primeiro lidando com a vida, nascimento, trabalho de parto e o segundo com a morte, os cuidados na terminalidade humana (Tabela 10).

As parturientes relataram efeitos como o alívio da dor durante as contrações, ambientalização da parturiente no hospital, auxilio na diminuição da tensão e do medo estímulo à oração e à espiritualidade. Pode-se evidenciar no estudo o reconhecimento da música pelo bebê, esse fato foi destacado nos discursos das mães e mencionado muitas vezes. A música auxiliou também na ambientalização do bebê quando foi preciso a mudança ou chegada no domicílio, após a alta da maternidade (TABARRO et al., 2010). Houve resultados positivos quanto ao uso da música para os cuidadores e a pessoa cuidada que experimenta a situação da terminalidade (Tabela 10).

É importante inserir a música no cuidado à terminalidade da vida, pois se acredita ser possível a humanização do cuidado através dela, já que contempla os preceitos filosóficos e humanísticos dos cuidados paliativos. Portanto é um recurso valioso no cuidado de enfermagem, levando em consideração o déficit de lazer e a monotonia do ambiente domiciliar (SALES et al., 2011).

Tabela 10 - Identificação dos resultados abordados nas publicações. Montes Claros (MG), 2012.

\begin{tabular}{|c|c|c|c|c|}
\hline Autor(es) & Título & Periódico & Ano & $\begin{array}{r}\text { Resultados } \\
\end{array}$ \\
\hline Tabarro et al. & $\begin{array}{l}\text { Efeito da música } \\
\text { no trabalho de } \\
\text { parto e no recém- } \\
\text { nascido }\end{array}$ & $\begin{array}{c}\text { Revista da } \\
\text { Escola de } \\
\text { Enfermagem da } \\
\text { USP }\end{array}$ & 2010 & $\begin{array}{c}\text { A análise dos discursos dessas mulheres } \\
\text { evidenciou efeitos surpreendentemente } \\
\text { favoráveis com relação a aspectos importantes } \\
\text { da vivência do trabalho de parto. (n. 15) }\end{array}$ \\
\hline Sales et al. & $\begin{array}{l}\text { A música na } \\
\text { terminalidade } \\
\text { humana: }\end{array}$ & $\begin{array}{l}\text { Revista da } \\
\text { Escola de } \\
\text { Enfermagem da }\end{array}$ & 2011 & $\begin{array}{l}\text { Os resultados mostraram que a utilização da } \\
\text { música no cuidado dos seres que vivenciam o } \\
\text { câncer pode proporcionar bem-estar aos }\end{array}$ \\
\hline
\end{tabular}


Fonte: Base de dados eletrônica - Biblioteca Virtual de Saúde (BVS). 2012.

\section{Instituição de longa permanência}

O artigo n. 09 abordou o uso da música para idosos institucionalizados, analisando a percepção dos músicos atuantes nesse ambiente (Tabela 11).

Os idosos, na maioria dos casos, ressentem-se da ausência de relações, pois a rede social apresenta uma tendência a diminuir à medida que se envelhece, tornando-se ainda mais agravante a partir da intitucionalização. Relaciona-se ainda a redução das oportunidades de substituição para essas perdas, assim os músicos, possibilitam por alguns momentos o preenchimento dessa lacuna. De certo modo, as instituições ao aceitarem o desenvolvimento de tal atividade passam a atuar como promotoras e mediadoras de uma nova possibilidade de rede de apoio, podendo contribuir para que haja também novas relações entre os internos (LEÃO; FLUSSER, 2008).

Tabela 11 - Identificação dos resultados abordados nas publicações. Montes Claros (MG), 2012.

\begin{tabular}{ccccc}
\hline Autor(es) & Título & Periódico & Ano & Resultados \\
\hline & Música para idosos & Revista da & & A música nas instituições de saúde é \\
Leão, Flusser & $\begin{array}{c}\text { institucionalizados: } \\
\text { percepção dos }\end{array}$ & $\begin{array}{c}\text { Escola de } \\
\text { Enfermagem da }\end{array}$ & 2008 & $\begin{array}{c}\text { necessária para a preservação da linguagem } \\
\text { para os idosos em processos efetivos de } \\
\end{array}$ \\
& músicos atuantes & USP & & comunicação. (n. 09)
\end{tabular}

Fonte: Base de dados eletrônica - Biblioteca Virtual de Saúde (BVS). 2012.

\section{Conclusões encontradas nas publicações estudadas}

As conclusões expressas nas publicações selecionadas para este estudo identificaram diversos resultados positivos obtidos com a intervenção musical, como a redução e controle da dor e de comportamentos causados por ela, desenvolvimento de novas estratégias de enfrentamento, alívio da ansiedade préoperatória nas crianças, diminuição da agitação e de comportamentos agressivos, relaxamento, redução da ansiedade, melhora dos parâmetros vitais (PA, FC, FR e saturação), redução de náuseas e vômitos, diminuição do medo e sofrimento, indução do sono, melhora nas habilidades cognitivas, sociais e físicas, modulação do humor, distração/divertimento, socialização, expressão de sentimentos, reabilitação e satisfação do cliente e familiares com o cuidado prestado e diversos outros benefícios que acompanham o uso da música de forma terapêutica. 
Quando as pessoas ouvem a música, elas não estão plenamente conscientes do impacto que estas podem causar. A música produz efeitos mentais e físicos. Algumas vezes elas são estimulantes e até mesmo evasivas. Possuindo o conhecimento da capacidade da música, é possível produzir efeitos específicos, de forma intencional (GONÇALEZ; NOGUEIRA; PUGGINA, 2008). Por isso a falta de conexão com o rock pode indicar que este não fazia parte do universo sonoro de grande parte do grupo de enfermeiros do estudo, já que é um gênero mais relacionado à afirmação da identidade da juventude, lidando de forma direta com a sexualidade e agressividade inerente a esta fase. Assim não correspondia ao momento de vida atual dos sujeitos da pesquisa, mesmo porque, além de pertencerem à outra faixa etária, o perfil profissional da enfermagem indica a necessidade de relaxamento, devido à intensa atividade motora e tensão que envolve o seu exercício profissional (BERGOLD; ALVIM; CABRAL, 2006).

Nenhum dos enfermeiros relatou utilizar a música diretamente na sua prática profissional. Contudo, alguns desses conhecem enfermeiros que têm buscado inserir a música na sua prática de educarcuidar junto ao cliente (BERGOLD; ALVIM; CABRAL, 2006). Essa situação evidencia também porque há pouco estudo científico interligando a música à enfermagem publicada nacionalmente.
Em virtude de todos os benefícios alcançados através da música e em uma visão desenvolvida da educação atual, não basta uma formação que contemple somente ciências básicas e humanas, mas também a percepção da influência da arte, especialmente da música, na demonstração da criatividade a fim de promover a singularidade, imprescindível no mundo globalizado de hoje, além da possibilidade de um recurso importante para equilibrar e humanizar o processo educacional (BERGOLD; ALVIM; CABRAL, 2006). Por outro lado, evidenciouse que os currículos dos cursos da área da saúde, têm dado pouco valor aos aspectos que ampliem o processo diagnóstico-terapêutico para além da área biológica. Por isso se faz necessário elaborar um currículo ampliado onde se somem aos atributos técnicos outros que incentivam e valorizem a experiência, a subjetividade, a estética, a criatividade e as artes (FERREIRA; REMEDI; LIMA, 2006).

\section{CONSIDERAÇÕES FINAIS}

Esta investigação possibilitou um contato maior com a literatura científica sobre o uso da música de forma terapêutica no ensino e cuidado da enfermagem, o que permitiu investigar a natureza dos artigos científicos que abordam a temática, publicados no período de 2004 a 2011.

Segundo apresentado ao decorrer desta pesquisa, o uso da música de forma 
terapêutica apresenta diversos efeitos e benefícios aos clientes que possuem a oportunidade do desenvolvimento desta terapia, tanto no âmbito biológico como no contexto social, psicológico, do autocuidado e ensino.

A escolha da música é um aspecto importante a ser analisado. O cliente deve se sentir a vontade com a mesma, possuir boas recordações caso seja conhecida para ele, e deve-se levar em conta o resultado pretendido. Músicas de andamento lento são relaxantes, já as músicas de andamento rápido podem ser estimulantes.

Evidenciaram-se, na análise dos artigos selecionados, que são poucos os profissionais da área da saúde que conhecem e usam a terapia desenvolvida com a música, sendo que é bastante escassa as publicações referentes ao tema publicadas pelos profissionais.

Todavia, notou-se nas publicações uma abrangência da abordagem na música em diversas áreas da saúde, os sujeitos pesquisados foram variados e de todas as faixas etárias, mas devido a pouca literatura encontrada percebe-se que ainda existem lacunas que precisam ser pesquisadas.

O profissional enfermeiro foi bastante abordado nas publicações selecionadas, mostrando o seu papel de integrar o cuidado com a humanização, proporcionando ao cliente alívio ou amenização do desconforto, porém ainda há pouco preparo do profissional de enfermagem pelas instituições de ensino, o que dificulta o desenvolvimento da terapia pelo mesmo.

De acordo com o que foi analisado neste estudo, a abordagem ao uso da música terapêutica ocorreu nas seguintes situações: em revisão de literatura; durante a internação hospitalar; no ambulatório; na universidade; no domicílio e em Instituições de Longa Permanência.

Observa-se que a maior parte das publicações selecionadas abordou o uso da música terapêutica na revisão de literatura. Porém houve referências ao ambiente hospitalar, o que comprova a sua eficácia nesse contexto de mudanças e experiências novas aos clientes. Há poucos estudos no que concerne ao ensino, o que corrobora as poucas publicações encontradas sobre a temática.

Os resultados desta pesquisa possibilitam inferir que a maior parte das publicações analisadas abordou a questão do uso da música terapêutica com a metodologia qualitativa, o que permite considerar a subjetividade das implicações do uso da música juntamente com os clientes, pois esta não é uma ciência exata, racional, onde as variáveis resultam sempre no mesmo resultado. Isso não exclui, no entanto, as investigações quantitativas que fizeram parte do estudo há, porém muito que se investigar e aprender sobre esta modalidade terapêutica que ganha espaço no contexto do cuidado e ensino. 
De acordo com o estudo, todos os sujeitos foram abordados de forma equivalente, pois a maioria explorou os clientes de uma forma geral, sem especificação da faixa etária, porém, nas publicações em que houve a discriminação dos sujeitos ficou evidente que os idosos foram pouco contextualizados na temática. Esse fato enfatiza a necessidade de estudos que abordem esse aspecto.

Os sujeitos do estudo, em sua maioria, estavam passando por algum processo que afetavam a sua saúde, o que mostra a necessidade de investigações com o uso da música para proporcionar a promoção de uma vida saudável, sem que o sujeito estudado esteja passando por algum processo debilitante, assim como foi pouco evidenciado estudos que apontam para o ensino.

O tema deste estudo, portanto, pode ser mais explorado e produzir publicações científicas disponibilizadas eletronicamente, a fim de que os profissionais de saúde possam delas usufruir, promovendo a ampliação do conhecimento e aperfeiçoamento do desenvolvimento da prática terapêutica abordada.

O desenvolvimento de métodos de abordagem da música terapêutica pode ser trabalhado durante a graduação com acadêmicos de enfermagem, mas também de outros cursos, possibilitando que toda a equipe esteja preparada para atender as necessidades do cliente e de seus familiares.

\section{REFERÊNCIAS}

ANDRADE, R. L. P.; PEDRÃO, L. J. Algumas considerações sobre a utilização de modalidades terapêuticas não tradicionais pelo enfermeiro na assistência de enfermagem psiquiátrica. Revista Latino-Americana de Enfermagem. São Paulo, v. 13, n. 5, p. 737742, 2005. Disponível em: http://www.scielo.br/pdf/rlae/v13n5/v13n5a1 9.pdf

ARNON, S. Intervenção musicoterápica no ambiente da unidade de terapia intensiva neonatal. Jornal de Pediatria (Rio de Janeiro). Rio de Janeiro, v. 87, n. 3, p. 183185, 2011. Disponível em: http://www.scielo.br/pdf/jped/v87n3/a01v87n 03.pdf

BERGOLD, L. B.; ALVIM, N. A. T. A música terapêutica como uma tecnologia aplicada ao cuidado e ao ensino de enfermagem. Escola Anna Nery Revista de Enfermagem. Rio de Janeiro, v. 13, n. 3, p. 537-542, 2009. Disponível em: http://www.scielo.br/pdf/ean/v13n3/v13n3a12 .pdf

BERGOLD, L. B.; ALVIM, N. A. T.; CABRAL, I. E. O lugar da música no espaço do cuidado terapêutico: sensibilizando enfermeiros com a dinâmica musical. Texto \& Contexto - Enfermagem. Florianópolis, v. 15, n. 2, p. 262-269, 2006. Disponível em: http://www.scielo.br/pdf/tce/v15n2/a09v15n2. pdf

BRITO, D. S.; FARIAS, F. A. C. Os efeitos da música no escolar cardiopata durante a punção venosa: estudo preliminar. Revista Paulista de Enfermagem. São Paulo, v. 24, n. 1, p. 47-56, 2005.

CORTE, B.; LODOVICI NETO, P. A musicoterapia na doença de Parkinson.

Ciência \& Saúde Coletiva. Rio de Janeiro, v. 
14, n. 6, p. 2295-2304, 2009. Disponível em: http://www.scielosp.org/pdf/csc/v14n6/38.pdf

FERREIRA, C. C. M.; REMEDI, P. P.; LIMA, R. A. G. A música como recurso no cuidado à criança hospitalizada: uma intervenção possível? Revista de Brasileira de Enfermagem. Brasília, v. 59, n. 5, p. 689693, 2006. Disponível em:

http://www.scielo.br/pdf/reben/v59n5/v59n5a $\underline{18 . p d f}$

FONSECA, K. C. et al. Credibilidade e efeitos da música como modalidade terapêutica em saúde. Revista Eletrônica de Enfermagem. Goiânia, v. 8, n. 3, p. 398-403, 2006. Disponível em:

http://www.fen.ufg.br/revista/revista8_3/v8n3 $\underline{\text { a10.htm }}$

GONÇALEZ, D. F. C.; NOGUEIRA, A. T. O.; PUGGINA, A. C. G. O uso da música na assistência de enfermagem no Brasil: uma revisão bibliográfica. Cogitare Enfermagem. Curitiba, v. 13, n. 4, p. 591-596, 2008. Disponível em:

http://ojs.c3sl.ufpr.br/ojs2/index.php/cogitare/ article/view/13121/8881

HATEM, T. P.; LIRA, P. I. C.; MATTOS, S. S. Efeito terapêutico da música em crianças em pós-operatório de cirurgia cardíaca.

Jornal de Pediatria (Rio de Janeiro). Rio de Janeiro, v. 82, n. 3, p. 186-192, 2006.

Disponível em:

http://www.scielo.br/pdf/jped/v82n3/v82n3a0 $\underline{\text { 6.pdf }}$

LEÃO, E. R.; FLUSSER, V. Música para idosos institucionalizados: percepção dos músicos atuantes. Revista da Escola de Enfermagem da USP. São Paulo, v. 42, n. 1, p. 73-80, 2008. Disponível em:

http://www.revistas.usp.br/reeusp/article/view $\underline{141708 / 45321}$

LEÃO, E. R.; SILVA, M. J. P. Música e dor crônica músculoesquelética: o potencial evocativo de imagens mentais. Revista Latino-Americana de Enfermagem. Ribeirão Preto, v. 12, n. 2, p. 235-241, 2004.
Disponível em:

http://www.scielo.br/pdf/rlae/v12n2/v12n2a1 3.pdf

MENDES, K. D. S.; SILVEIRA, R. C. C. P.; GALVÃO, C. M. Revisão integrativa: método de pesquisa para a incorporação de evidências na saúde e na enfermagem. Texto \&

Contexto - Enfermagem. Florianópolis, v. 17, n. 4, p. 758-764, 2008. Disponível em: http://www.scielo.br/pdf/tce/v17n4/18.pdf

NOGUEIRA, M. A. A música e o desenvolvimento da criança. Revista UFG. Goiânia, v. 5, n. 2, p. 1-7, 2003. Disponível em:

http://www.proec.ufg.br/revista_ufg/infancia/ G_musica.html

PICADO, S. B. R.; EL-KHOURI, R. N.; STREAPCO, P. T. Humanização hospitalar infantil: intervenções musicoterapêuticas no centro clínico Electra Bonini. Pediatria (São Paulo). São Paulo, v. 29, n. 2, p. 99-108, 2007. Disponível em: http://pediatriasaopaulo.usp.br/upload/pdf/121 2.pdf

SALES, C. A. et al. A música na terminalidade humana: concepções dos familiares. Revista da Escola de Enfermagem da USP. São Paulo, v. 45, n. 1, p. 138-145, 2011. Disponível em: http://www.scielo.br/pdf/reeusp/v45n1/19.pdf

SEKI, N. H.; GALHEIGO, S. M. O uso da música nos cuidados paliativos: humanizando o cuidado e facilitando o adeus. Interface Comunicação, Saúde \& Educação.

Botucatu, v. 14, n. 33, p. 273-284, 2010. Disponível em: http://www.scielo.br/pdf/icse/v14n33/a04v14 $\underline{\text { n33.pdf }}$

SILVA, A. S. et al. Efeito terapêutico da música em portador de insuficiência renal crônica em hemodiálise. Revista

Enfermagem UERJ. Rio de Janeiro, v. 16, n. 3, p. 382-387, 2008. Disponível em: http://www.facenf.uerj.br/v16n3/v16n3a14.pd $\underline{f}$ 
TABARRO, C. S. et al. Efeito da música no trabalho de parto e no recém-nascido. Revista da Escola de Enfermagem da USP. São

Paulo, v. 44, n. 2, p. 445-452, 2010.

Disponível em:

http://www.scielo.br/pdf/reeusp/v44n2/29.pdf

TODRES, I. D. Música é remédio para o coração. Jornal de Pediatria (Rio de

Janeiro). Rio de Janeiro, v. 82, n. 3, p. 166168, 2006. Disponível em:

http://www.scielo.br/pdf/jped/v82n3/v82n3a0

2.pdf

VIANNA, M. N. S. et al. A musicoterapia pode aumentar os índices de aleitamento materno entre mães de recém-nascidos prematuros: ensaio clínico randomizado controlado. Jornal de Pediatria (Rio de Janeiro). Rio de Janeiro, v. 87, n. 3, p. 206212, 2011. Disponível em: http://www.scielo.br/pdf/jped/v87n3/a05v87n 03.pdf

ZANINI, C. R. O. et al. O efeito da musicoterapia na qualidade de vida e na pressão arterial do paciente hipertenso. Arquivo Brasileiro de Cardiologia. Rio de Janeiro, v. 93, n. 5, p. 534-540, 2009. Disponível em: http://www.scielo.br/pdf/abc/v93n5/a15v93n5 .pdf 